\title{
Surgical treatment in asymptomatic patients with duodenal ulcers as a prophylaxis against haemorrhage
}

\author{
T. E. BUCKNALL \\ M.S., F.R.C.S.
}

C. WASTELL

M.S., F.R.C.S.

Surgical Unit, Westminster Hospital, London SWIP 2AP

In a group of 17 patients who underwent surgery for chronic duodenal ulceration because of past bleeding but without current symptoms, one patient re-bled with a follow-up of 81 patient years, as compared to one bleed over 6.8 patient years before surgery. This suggests that surgery is protecting these patients against recurrent episodes of haemorrhage.

\section{Introduction}

Occasionally, a patient with chronic duodenal ulceration presents with bleeding associated with very little else in the way of symptoms. The results of the British Society of Gastroenterology survey of management in upper gastro-intestinal haemorrhage were published in 1980 (Thomas et al., 1980). Respondents were asked for their recommendations regarding surgery in a hypothetical patient with a duodenal ulcer and previous minor dyspepsia who has an episode of acute bleeding which stops after blood transfusion of 4 units. The absence of data guiding the surgeon in his decision is shown by the survey's results; that is, $20 \%$ never operate, $8 \%$ always do, with $72 \%$ split between 'sometimes' and 'usually'. Since haemorrhage is the most dangerous complication in this condition, it is important too establish how such patients can be protected for the future. Accordingly, patients who presented with $\overbrace{\infty}$ haemorrhage from their duodenal ulcers, who were $\dot{\sigma}$ otherwise virtually asymptomatic and who were or treated surgically, were followed-up to see if other $\omega_{0}$ bleeding episodes had occurred.

\section{Methods}

From a retrospective review of all patients undergoing surgery for duodenal ulcer in the $10^{\gtrless}$ years from 1970 to 1980,17 were identified wh $\vec{\oplus}$ had previously had significant episodes of bleeding, were not bleeding at the time of the decision operate and who had little in the way of indigestion or other symptoms that could be associated with chronic duodenal ulceration. The details of the patients are recorded in Table 1.

Apart from clinical evidence the diagnosis was established by barium meal alone in 7 patients, by endoscopy alone in 3 , and by a combination of both barium meal and endoscopy in the remainder.

TABle 1. Pre-operative data

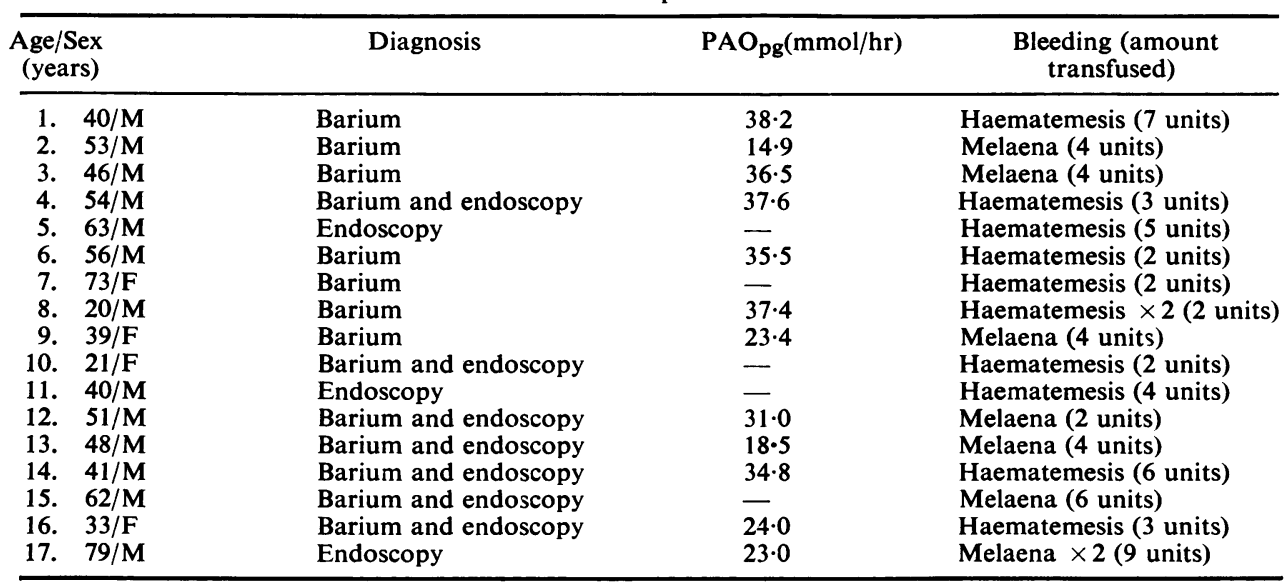

PAO $_{\mathrm{pg}}=$ Peak acid output to pentagastrin.

0032-5473/82/0100-0030 $\$ 02.00$ (C) 1982 The Fellowship of Postgraduate Medicine 


\section{Results}

\section{Extent of haemorrhage}

Haematemesis occurred in 10 patients, melaena alone in the remaining 7 . In 19 bleeding episodes in these 17 patients average blood replacement was 4 units. The least blood given was 2 units and the most 9 units.

Ten patients had a haemoglobin of less than $10.5 \mathrm{~g} / \mathrm{dl}$ when admitted for the active bleeding episode.

\section{Peak acid output to pentagastrin}

This was measured in 12 of the 17 patients, the mean secretion being $29.6 \mathrm{mmol} / \mathrm{hr}$ (s.d. 8.32, range $14 \cdot 9-38 \cdot 2$ ).

\section{Surgical treatment}

Eleven patients underwent proximal gastric vagotomy (PGV) alone; one patient received PGV with pyloroplasty of a modified Finney type $\left(\mathbf{P}_{\mathbf{f}}\right)$; 4 patients underwent selective vagotomy, 2 with pyloroplasty, one with gastro-jejunostomy and one with an antrectomy of Billroth II type. (The patient who underwent selective vagotomy with gastrojejunostomy in 1975 subsequently perforated in 1977 and an antrectomy of the Billroth I type was then carried out); one patient underwent truncal vagotomy and pyloroplasty.

\section{Follow-up (see Table 2)}

Following surgery, patients are seen at intervals of 3 months, 6 months, one year and thereafter annually and all patients within this follow-up have

TABLE 2. Operation and postoperative follow-up

\begin{tabular}{|c|c|c|c|}
\hline \multicolumn{2}{|r|}{ Operation } & $\begin{array}{c}\text { Follow-up } \\
\text { (years) }\end{array}$ & Visick grade \\
\hline 1. & PGV 1970 & 10 & I \\
\hline 2. & $S V$ and $P_{f} 1972$ & 8 & II \\
\hline 3. & $S V$ and $P_{f} 1972$ & 8 & $(I V) * I I$ \\
\hline 4. & $P G V$ and $P_{f} 1973$ & 7 & I \\
\hline 5. & $T V$ and $P_{f} 1973$ & 7 & I \\
\hline 6. & PGV 1974 & 6 & I \\
\hline 7. & PGV 1974 & 6 & I \\
\hline 8. & PGV 1975 & 5 & I \\
\hline 9. & PGV 1975 & 5 & I \\
\hline 10. & SV and GJ (1975) & 5 & (IV) \\
\hline & BI 1977 & & I \\
\hline 11. & PGV 1976 & 4 & III \\
\hline 12. & PGV 1977 & 3 & I \\
\hline 13. & PGV 1978 & 2 & I \\
\hline 14. & PGV 1978 & 2 & II \\
\hline 15. & SV and BII 1979 & 1 & I \\
\hline 16. & PGV 1979 & 1 & I \\
\hline & PGV 1979 & 1 & I \\
\hline
\end{tabular}

*=re-bled; $\mathrm{PGV}=$ proximal gastric vagotomy; $\mathrm{SV}=$ selective vagotomy; $P_{f}=$ pyloroplasty of a modified Finney type; $\quad T V=$ truncal vagotomy; $G J=$ gastro-jejunostomy; $\mathrm{BI}=$ Billroth I-type antrectomy; BII = Billroth II-type antrectomy. been seen within the last year (1981). The average time from operation is 4 years and 8 months with a range from one to 10 years.

\section{Re-bleeding and recurrence}

One patient has suffered an episode of re-bleeding. In 1972 selective vagotomy and pyloroplasty was performed and a recurrent episode of haemorrhage occurred in 1976. No further operation or further treatment was required and on this occasion blood transfusion was not required.

The patient who underwent selective vagotomy and gastro-jejunostomy in 1975 perforated a gastro-jejunal ulcer in 1977 and at the time of this perforation an antrectomy was performed with a Billroth I type of anastomosis. She has remained well following this episode of recurrent ulceration.

\section{Discussion}

A group of patients was chosen for whom the decision to operate was unusually difficult. They had all had significant and even dangerous bleeding episodes in the past but had nothing in the way of serious indigestion at the time of operation. The decision therefore related to a 'trade-off' between on the one hand protection against bleeding in the future and on the other, the likelihood of developing post-vagotomy symptoms after surgery, such as dumping, bilious vomiting or diarrhoea.

Bleeding from a duodenal ulcer is the most hazardous complication and accounts for nearly $50 \%$ of the deaths due directly to ulcer disease (Wangensteen, 1954). Pulvertaft (1968) found that if duodenal ulcers present with haemorrhage in a man there was a $75 \%$ chance that re-bleeding would occur within 10 years or, alternatively, that one bleeding episode could be expected for 13.33 patient years. There seemed good reason to suppose, therefore, that not only would these patients rebleed but also this would be attended by significant danger. So far only one of the group has had an episode of re-bleeding, which represents one bleed for 81 patient years compared to one bleed for 6.8 patient years before surgery. The episodes of recurrence and bleeding have both occurred within 4 years of operation, and this suggests that surgery is protecting the patients against recurrent episodes of haemorrhage.

\section{References}

Pulvertaft, C.N. (1968) Comments on the incidence and natural history of gastric and duodenal ulcer. Postgraduate Medical Journal, 44, 597.

Thomas, C.E., Cotton, P.B., Clark, C.G. \& Boulos, P.B. (1980) Survey of management in acute upper gastrointestinal haemorrhage. Journal of the Royal Society of Medicine, 73, 90.

WANGENSTEEN, O.H. (1954) The surgical treatment of peptic ulcer. Journal of the Iowa State Medical Society, 44, 365. 